\title{
Optimizing Assignment Design for Primary and Secondary School Students
}

\author{
Xiuwang Huang \\ Teaching Research Office of Jiangning District in Nanjing, Nanjing, \\ Jiangsu, China
}

Abstract: One of the most essential connections among all assignment tasks is assignment design. The design of high-quality assignments is critical to achieving successful homework outcomes. This study explores the existing research on the roles of assignment design and highlights the current state of assignment design in China's primary and secondary schools. In terms of assignment loads, content, formats, and stratification, suggestions are made.

Science Insights Education Frontiers 2022; 11(1):1509-1516.

Doi: 10.15354/sief.22.or014

How to Cite: Huang, X. (2022). Optimizing assignment design for primary and secondary school students. Science Insights Education Frontiers, 11(1):15091516.

Keywords: Student Assignment, Assignment Design, Assignment Loads, Assignment Contents, Assignment Stratification, Primary and Secondary Students

Correspondence to: Xiuwang Huang, Teaching Research Office of Jiangning District in Nanjing, Nanjing, China. Email:njdwhxw@126.com

Conflict of Interests: None.

(C) 2022 Insights Publisher. All rights reserved.

Creative Commons NonCommercial CC BY-NC: This article is distributed under the terms of the Creative Commons Attribution-NonCommercial 4.0 License (http://www.creativecommons.org/licenses/by$\mathrm{nc} / 4.0 /$ ) which permits non-commercial use, reproduction and distribution of the work without further permission provided the original work is attributed by the Insights Publisher. 
CHOOL assignments are an integral part of educational activities. They suppleO ment classroom instruction. They are an integral part of student learning and assignments that students must do independently. The quality of an assignment's design is a significant factor in determining how well it is completed. Enhancing assignment design involves both theoretical underpinnings and effective design techniques. This paper examines existing issues with assignment design in primary and secondary schools in China and makes recommendations for improving assignment design. These include limiting uniform assignment loads and increasing student discretionary study time, diversifying assignment content and forms, and utilizing educational technology to adjust and personalize assignments.

\section{Connotations and Functions of Student Assignments}

Assignments serve as extensions of classroom learning, consolidating memorization and stimulating information application through various methods such as recalls and linkages. Teachers receive feedback on their instruction via assignment scores and adjust their instruction accordingly (Zhang, 2017). There are preparation assignments prior to class, in-class assignments, and post-class assignments to review. There are three types of assignments: in-class tasks, homework, and social practical exercises. Additionally, school tasks can be spoken or written. Each assignment has a distinct purpose.

Consolidating classroom knowledge is the most widely acknowledged function of school assignments. According to researchers, assignments are extensions of classroom learning, systematizing what is learned in class and enhancing students' comprehension and memory of the material ( $\mathrm{Hu}, 2019)$. Following a learning activity with a specified number of exercises enables students to apply basic knowledge, transform it into components of their knowledge structure, and build their thinking capacity.

Assignments, like examinations, serve as assessment instruments. This function bestows the tester role on assignments. Tulving's experiment established the usefulness of testing in retaining knowledge memory (Tulving, 1985). Based on Tulving's experiment, researchers evaluated a variety of exams (assignments included) and discovered that people who had encountered the tests had a higher level of memory retention than those who had learned without encountering any tests (Kang, 2007; Zhang et al., 2008). As with any other test, assignments show a student's level of understanding. By assessing students' assignments, teachers can determine students' understanding of content, analyze the root causes of issues, and assist students in identifying solutions.

Assignments also have an effect on students' development of different abilities and family relationships. Ramdass and Zimmerman (2011) concluded from their research that homework can help students develop self-management skills. They thought that homework stimulates students to continue their learning efforts, assists them in developing learning techniques, and strengthens their ability to concentrate, self-regulate, and manage their time effectively. Additionally, schoolwork strengthens family ties. Students can perceive a strong bond between their families and schools as a result of their parents' interest in and attention to their academic work (Cooper, 1989). 


\section{Currently, there Exist Issues with Assignment Design}

Assignment activity is comprised of five primary components: assignment design, assignment completion, assignment marking, comment on assignment results, and assignment review. Among them, assignment design takes the lead, as well-designed assignments can alleviate excessive schoolwork and boost students' overall growth. A detailed assessment of the assignment design status quo in China's primary and secondary schools reveals the following difficulties:

\section{Unreasonably High Assignment Loads}

Student assignment loads are often quantified in terms of the total amount of time spent on homework each week, a method widely recognized by researchers due to the difficulty of quantifying assignment loads in terms of pieces of work, word count, or pages (Li \& Xu, 2012; Hu, 2019). Additionally, some studies quantify assignment load using two additional terms: frequency (how frequently the teacher offers homework) and duration (how long it takes to complete each assignment) (Cooper, 1989). According to the 2015 results of the Program of International Student Assessment (PISA), each Chinese student spends an average of three hours a day on homework, twice the global average and three, four, and six times that of their French, Japanese, and Korean counterparts, respectively (OECD, 2016). According to PISA 2018 results, the average amount of time spent studying by Chinese students is likewise the highest in the world, at 57 hours per week, 44 hours more than the OECD average (OECD, 2019).

\section{Monotonic Assignment Contents and Forms}

Current tasks are typically limited to exercises from textbooks and additional materials. Wang (2012) discovered that teachers frequently provide repetitive activities as homework and that there are few assignments with expanded substance. However, mindless replication of textbook exercises and teaching materials detracts not only from students' motivation to complete assigned work, but also from their development of divergent thinking, which is detrimental to growing students' innovative consciousness and practical ability.

Additionally, homework can consist of both practical tasks and written assignments; it can be assigned individually or in groups. Nonetheless, the majority of schoolwork is now required to be done independently and in writing. Wang (2012) observed that the majority of students complete their schoolwork independently, with little assistance from others. According to a survey of five Chinese provinces, elementary school pupils in China today receive the majority of their homework in the form of written assignments, with no oral presentations, appreciations, or practical tasks (Ren, 2015).

\section{The Uniform Difficulty of Student Assignments with- out Stratification}


Assignments are classified according to their relevance to different students and to the assignment options available to students at various academic levels. Given the academic foundations and learning abilities of pupils, assignments of uniform difficulty cannot suit the learning demands of all students. However, due to the large class sizes prevalent in the majority of Chinese institutions, the teacher frequently assigns the same homework to the entire class. As a result, advantaged students' learning abilities cannot be fully developed through assignment completion, while underprivileged pupils are forced to battle with homework that is excessively difficult for them (Chen, 2021).

\section{Suggestions for Increasing the Efficiency of Student Assignments}

\section{Create Manageable Assignment Loads}

A time restriction for uniform assignments must be established for pupils in different grades. According to data research, there is an appropriate assignment load for pupils in each grade. Cooper (2001) discovered that homework has varying effects on academic performance among kids of various ages, with the biggest influence on senior high school students, the smallest effect on junior high school students, and no effect on primary school pupils. Cooper and Valentine's (2001) findings showing there is minimal association between the amount of homework completed by pupils of young ages and their academic progress bolstered this conclusion. For older student groups, the effect of homework burdens increases with age. At X School in Jiangsu Province, a strict policy is in place to control assignment loads. For first and second graders, there are no written assignments; for children in third through sixth grades, there are no more than 60 minutes of assignments. Tasks for students in grades 7-9 are limited to 90 minutes; all assignments must be completed in a self-study class.

Additionally, teachers must ensure that students have adequate study time. It is widely known that each grade level has an appropriate period of assignment time. Another point worth noting is that each student's requirement for assignment time is unique (Wang, 2015). Apart from establishing an appropriate load of uniform tasks, we must also consider students' requirements for discretionary assignment time, or time for students to complete academic work at their leisure. Therefore, teachers should not just cram their planned assignments into students' after-class time, but rather actively help students in making the most use of their homework time and completing their own after-class chores in accordance with their learning settings. In this manner, students may fine-tune their study techniques and learn to manage their time more effectively.

\section{Enhance the Content of Assignments and Diversify their Formats}


Another point worth exploring is how assignment design can assist in piqueing students' interest in studying. Wang and Zhang (2016) concluded, after examining 33,000 homework records, that student interest in homework has a greater impact on academic progress than homework load. As a result, assignment design should prioritize piqueing students' enthusiasm for studying. Enhancing the substance of assignments and incorporating new formats might help students maintain a proactive and enduring learning attitude.

Appropriate assignment contents guarantee that students achieve the assignment's objectives. The assignment's content should closely correspond to the learning objectives and be relevant to real life. When students make the connection between assignments and life, assignments become more relevant to them, and they devote more attention to completing academics (Wang \& Zhang, 2014). Additionally, diversification of materials contributes to the enrichment of assignment content. Teachers should broaden the scope of assignment materials in accordance with existing instructional objectives and content. Any readily available materials that contribute to the achievement of the objectives can be incorporated into the assignment design, including students' prior life experiences, community events, social and environmental phenomena, and so on (Lu, 2012).

Not only can a variety of assignment types increase students' interest in homework, but it also helps lessen students' feelings of academic stress. Apart from conventional assignments that emphasize knowledge comprehension and memorization, other engaging and difficult kinds of assignment design, such as projects and inquiries, should be incorporated to help students enhance their thinking talents, skills, and competence. A diverse range of assignments stimulates students' enthusiasm for learning, broadens their vision, and develops their capacities for inquiry and innovation.

\section{Improve Learning Efficiency by Utilizing Data Collec- tion and Analysis Technology}

Prompt feedback on assignment results is critical for academic performance improvement. According to several studies, online assignments with prompt feedback are more efficient and successful than traditional assignments (Mendicino et al., 2009; Singh, et al., 2011; Zhao, 2017). Due to their detrimental effect on student development, the majority of primary and secondary schools in China have begun to phase out the use of intelligent devices such as iPads and smart phones for assignment fulfillment. How can we enhance the timeliness of assignment feedback without altering the current practice of students answering questions on paper and teachers' marking with red pens? The solution may lie in data acquisition technology.

As with the answer collection technology that has been widely employed in large-scale examinations, assignment data collection employs scanning technology, but at a greater frequency (regular data collection of daily, weekly, or unit assignments), a faster collection speed, and a higher recognition rate. After students have completed the written responses to the questions, they spend a few minutes (2-5 minutes) filling out 
the weekly or unit assignment data gathering cards. Similarly, scanning the acquisition cards takes teachers only a few minutes (no more than five minutes). They are obligated to provide timely feedback on the findings of data collection.

The collected data can be used to tailor assignments to students' academic levels. The stratification of assignments according to age groups has been studied in detail. However, there is no indication that these research findings apply to individual members of the organization. For example, Cooper (1989) established a guideline for assignment design in which the assignment load for each grade equals 10 minutes multiplied by the grade number. According to this guideline, grade 3 pupils are allotted 30 minutes for assignments. This assignment load can be completed in less than ten minutes for advantaged students, while it may take up to sixty minutes for disadvantaged students. This also holds true for the assignment's difficulty. Certain individuals believe that failures (which typically refer to extremely difficult questions) push students to exert greater effort. Nonetheless, it is correct only for those kids who are persistent. Analyses of the collected data can assist teachers in determining each student's actual learning condition. It entails analyzing the questions and responses provided by students in specific assignments as well as analyzing the student's aggregated data in order to generate an overall picture of his task fulfillment. Additionally, assignment outcomes should be compared to examination results in order to identify implicit teaching errors. According to the analysis above, incorrect responses will be identified as uniform or personal, allowing teachers to change the difficulty of tasks and create stratified assignments for students with varying academic levels.

In sum, high-quality assignment design is critical for increasing student academic accomplishment, reducing unnecessary workload, and promoting students' holistic growth in a variety of abilities. To optimize assignment design, the total workload of the assignment should be kept to a manageable level and students should be given sufficient discretionary study time; assignment content and forms should be varied to maintain students' interest in learning; and educational technology should be used appropriately for assignment adjustment and stratification. All of these suggestions are meant to serve as a guide and reference for designing primary and secondary school assignments with the goal of increasing the efficiency and effectiveness of teaching and learning.

\section{References}

Chen, Y.Q. (2021). Stratified homework design of mathematics in middle grades of primary schools based on individual differences. Test Questions and Research, 2021(2):195-196.
Cooper, H. (1989). Homework. Longman. DOI: https://doi.org/10.1037/11578-000

Cooper, H. (2001). Homework for All--in Moderation. Educational Leadership, 58(7):3438. 
Cooper, H., \& Valentine, J.C. (2001) Using research to answer practical questions about homework. Educational Psychologist, 36 (3):143-153, DOI: https://doi.org/10.1207/S15326985EP3603 1

Hu, H.Y. (2019). Optimizing mathematics homework helps improve mathematics achievements -- A study on mathematics homework loads and subject achievements in junior middle schools. Reference for Middle School Teaching, 2019(24):30-31.

$\mathrm{Hu}$, Y.Y. (2019). On the reconstruction of the concept of "homework" in basic education. Educational Science Research, 2019(10):4752.

Jiang, Q. (1935). History of modern Western education. Beijing: China Commercial Press.

Kang, S.H.K., McDermott, K.B., \& Roediger, H. (2007). Test format and corrective feedback modulate the effect of testing on memory retention. European Journal of Cognitive Psychology, 19(4):528-558. DOI: https://doi.org/10.1080/09541440601056620

Li, J. \& Xu, J.P. (2012). An empirical study on the effect of homework on students' academic performance - A case study of Ningbo City in Zhejiang Province. School Administration, 2012(12): 4-6.

Lu, L. (2012). Research on optimal homework design in primary schools (Master's thesis). Zhejiang Normal University. DOI: https://doi.org/10.7666/d. y2194205

Mendicino, M., Razzaq, L., \& Heffernan, N.T. (2009). A comparison of traditional homework to computer-supported homework. Journal of Research on Technology in Education, 41(3):331-359. DOI: https://doi.org/10.1080/15391523.2009.1078 2534

OECD (2016), PISA 2015 Results (Volume II): Policies and Practices for Successful Schools, Paris: OECD Publishing. DOI: https://doi.org/10.1787/9789264267510-en OECD (2019), PISA 2018 Results (Volume I): What Students Know and Can Do, Paris OECD Publishing. DOI: https://doi.org/10.1787/5f07c754-en

Ramdass, D. \& Zimmerman, B.J. (2011). Developing self-regulation skills: The important role of homework. Journal of advanced academics, 22(2):194-218. DOI: https://doi.org/10.1177/1932202X11022002 $\underline{02}$

Ren, P. G. (2015). A survey on the status quo of homework in primary and secondary schools in five provinces of China. Educational Science Research, 2015(12):49-56.

Singh, R., Saleem, M., Pradhan, P., Heffernan, C., Heffernan, N.T., Razzaq, L., Dailey, M.D., O'Connor, C., \& Mulcahy, C. (2011). Feedback during web-based homework: the role of hints. In International Conference on Artificial Intelligence in Education (pp. 328336). Springer, Berlin, Heidelberg. DOI: https://doi.org/10.1007/978-3-642-218699_43

Tulving, E. (1985). Memory and consciousness. Canadian Psychology, 26(1):1. DOI: https://doi.org/10.1037/h0080017

Wang, J. X. (2012). The survey on the status quo of primary homework and its improvement strategies. Journal of Teaching and Management, 2012(26):22-24.

Wang, Y. F., \& Zhang, X. Y. (2014). Analysis on assignments based on 30000 data. Shanghai: East China Normal University Press. ISBN: 9787567527034.

Wang, Y.F. (2015). Homework design from the perspective of curriculum (doctoral dissertation). East China Normal University. https://kns.cnki.net/KCMS/detail/detail.aspx $?$ dbname $=$ CDFDLAST2017 \&filename $=101$ 5348181.nh

Wang, Y.F., \& Zhang, X.Y. (2016). Analysis on homework effect and homework burden. Modern Teaching, 2016(Z1): 8-10.

Zhang, J. (2017). A review of the nature and necessity of homework. Journal of Yibin University, 2017(8):23-30. DOI:

https://doi.org/10.19504/j. cnki. issn16715365.2017.08.004

Zhang, J.K., Bai, X.J., \& Yang, L.X. (2008). An overview of foreign research on the effect of tests. Advances in Psychological Science, 2008(4):661-670.

Zhao, H.H. (2017). An empirical study on the effect of homework feedback on junior secondary homework quality (Master's thesis). Ningbo University. 
Huang (China). Assignment Design for Primary and Secondary School Students. 

Huang (China). Assignment Design for Primary and Secondary School Students. 